\title{
Professionalism Characteristics of Nurses Working in Internal Medicine Clinics
}

\author{
Sevilay Hintistan*, Burcu Topcuoglu \\ Department of Internal Medicine Nursing, Faculty of Health Science, Karadeniz Technical University, Turkey
}

Copyright $\subset 2017$ by authors, all rights reserved. Authors agree that this article remains permanently open access under the terms of the Creative Commons Attribution License 4.0 International License

\begin{abstract}
Although there has long been a focus on professionalism in nursing in many countries, it is just now gaining importance in Turkey. In fact, few studies on this topic have been conducted in our country, and this is the first study carried out in the Eastern Black Sea region of Turkey. The aim of the current study was to determine professionalism characteristics of nurses working in the internal medicine clinics of a university hospital located in Trabzon Province. This descriptive study was done with 103 nurses between Feb.1 and Feb. 28, 2015. The data were gathered using a "Personal Information Form" and a "Professionalism Information Form" through face-to-face interviews. To assess the data, numbers, percentages and arithmetical means were employed. In the current study, $95.1 \%$ of the participating nurses were female. Their mean age was $31.54+7.42$ years, $66.0 \%$ of them had an undergraduate degree, $85.4 \%$ were clinic nurses, and their average work duration was $8 \pm 6.2$ years. This current study determined that nurses thought the most important professionalism characteristics were "taking individual responsibility in nursing practices (92.2\%)" and "paying attention to using a simple and clear language by establishing a good communication with patients and team members $(90.3 \%)$ ". The characteristics of "becoming a member of a nursing association (24.3\%)" and "feeling the necessity to use the titles of specialist nurse, doctorate nurse (19.4\%)" were less meaningful to our study participants.
\end{abstract} Keywords Internal Medicine Clinics, Nurse,
Professionalism

\section{Introduction}

According to the Webster's dictionary, professionalism is "the conduct, aims, or qualities that characterize or mark a profession or a professional person". It is also the recognition and acceptance of the knowledge, skills, and values required of those who have been trained in that profession [1]. Individuals with professionalism characteristics choose a field as a profession, become experts in the field by specialization, become competent in the field, follow developments in the field, contribute to problem-solving efforts and work efficiently with their team members $[2,3,4]$.

Achieving professional status is an important goal in nursing as in all disciplines. The International Council of Nurses (ICN) defines nursing as a profession that helps to protect the health of individuals, families and communities and participates in rehabilitation and treatment protocols in case of illness. Nurses are members of the nursing profession which plays an active role in the development and implementation of treatment and training protocols of the health care team [5]. Professionalism is important in the establishment of nursing care standards and provision of quality services [2]. However, professionalism in nursing is a complex concept [6]. Throughout the world and in our country the nursing profession has been evolving from a traditional nursing model to a professional nursing model. Scientific studies have reported that members of most professions are required throughout their careers to continue in their professional improvement and education. This requires being open to advancements and possessing both intellectual and investigative backgrounds and interests which manifest through responsible leadership and effective communication. In this way, nurses can advance in the career of professional nursing [3].

The basic objective in the provision and management of nursing services is to offer quality health care. To achieve this goal, nurses will be required to conduct studies, establish theories and participate in professional organizations and political activities [2]. However, the studies conducted thus far have reported that the mean professionalism scores of nurses' autonomy, membership in professional associations, and written scientific articles are low [7, 8].

It is very important for nurses to project the characteristics and values of professionalism in the nursing profession. These include educational preparation, conducting research, reading publications, providing community trainings, 
participating in professional organizations, adhering to nursing codes, exhibiting autonomy, and showing competence with sufficient theoretical knowledge and continuing education $[3,9,10]$.

Patients who receive treatment and care at internal medicine clinics are those with very serious health issues, long-term care needs, or treatment challenges. Nurses working at these clinics often witness the physical and psychological pain of patients and their families in life-threatening situations [11]. Therefore, internal medicine nurses serve individuals with high stress health crises, and they themselves suffer intense stress as well. Indeed, in addition to the demands of their professional lives, most of the internal medicine nurses are female who already are struggling to combine the responsibilities of womanhood, motherhood, and the social pressures associated with those roles [5]. In the Zakari, Al Khamis and Hamadi study on how nurses perceived the concepts of professionalism and conflict, most of the nurses perceived their professionalism at low levels [12]. This should cause great concern within the nursing field. When professionalism is not practiced by the internal medicine nurses the consequences can lead to compromised care services, reduced quality of care, and dissatisfaction among those offering services and receiving services. Organizational problems may be the result, which can negatively impact the professionalism of internal medicine nurses [5].

The efficacy of nursing care provided to patients hospitalized at internal medicine clinics depends on nurses' ability to display professional characteristics such as professional knowledge, autonomy, and discipline [13, 14, 15]. The importance of professionalism and the ability of internal medicine nurses to offer care and services at a satisfactory level are an absolute necessity. Furthermore, should difficulties in providing services arise, the need to maintain professionalism as problems are solved is equally important [9, 10]. Acquisition of professionalism characteristics by internal medicine nurses enhances quality of nursing services and reduces errors. It also provides a path to professional advancement and specialization and boosts performances and satisfaction with the job and nursing services $[11,16]$. Other advantages are that the hospital stays of patients and costs in health services decrease [2, 17]. A study on the effect of job satisfaction upon professional behaviors found a significant and positive correlation between them [18].

We believe that more studies are needed which explore the professional characteristics of internal medicine nurses. More research on this topic will contribute to the ongoing need for nurses to remain cognizant of the importance of continual professional growth and development. The current study was undertaken to determine the professionalism characteristics of internal medicine nurses employed at internal medicine clinics.

\section{Material Method}

\subsection{Type and Place of the Study}

The current study, in descriptive design, was undertaken at Internal Medicine Clinics of a university hospital located in Trabzon Province, Turkey.

\subsection{Population and Sample of the Study}

The population of the study consisted of 153 nurses working at the Internal Medicine Clinics of a university hospital located in Trabzon Province. No sampling was made and the whole population was targeted. However, for various reasons the study was completed with 103 nurses. Twenty-three nurses were off duty or on sick leave, seven nurses were out of Trabzon Province due to educational commitments, sixteen nurses declined to participate in the study and four nurses transferred to another clinic between Feb. 1 and Feb. 28, 2015. Nurses who worked at internal medicine clinics and volunteered to participate in the study were recruited for the study.

\subsection{Data Collection Tools}

The data were collected using the "Personal Information Form" and the "Professionalism Information Form".

\subsubsection{Personal Information Form}

The "Personal Information Form" was designed by the researchers after a literature review. The form included seven questions addressing nurses" "sex, age, marital status, educational level, clinic where nurses worked, work-position and work-duration".

\subsubsection{Professionalism Information Form}

The "Professionalism Information Form" was designed by the researchers after a literature review. There were 24 questions to determine professionalism characteristics of nurses working in internal medicine clinics. The questions were as follows: "do you take individual responsibility in nursing practices?"; "do you pay attention to division of labor in team work?"; "do you demonstrate positive attitudes while offering nursing services?"; "do you make efforts to produce different and customized nursing services for each patient?"; "do you perform your nursing duties in a professional manner?"; "do you support association/society related activities?"; "do you use evidence-based study results in nursing practices?"; "do you follow scientific and technological developments and advancements in nursing?"; "do you promote constructive and positive conditions and actions in nursing practices?"; “do you feel the necessity to use titles of specialty nurse, doctorate nurse?" etc.). The questions were answered as "yes", "no" and "partly". 


\subsection{Implementation of Data Collection Tools}

The "Personal Information Form" and "Professionalism Information Form" were administered to nurses who worked at internal medicine clinics and who had volunteered to participate in the study through face-to face-interviews. The study took place Feb. 1 to Feb. 28, 2015, and participants needed about 20 minutes to complete the forms.

\subsection{Assessment of the Data}

The Statistical Package for the Social Sciences (SPSS 18.0) was employed for the assessment of the data obtained from the study, and number, percentages and average scores were used.

\subsection{Ethical Suitability of the Study}

Before the study, the ethical suitability of the research was approved by the Office of the Head Physician of Farabi Hospital of Medicine Faculty of Karadeniz Technical University. In addition, all patients were informed of the purpose of the study and gave their informed consent to take part in the study.

\section{Results}

For this current study, $95.1 \%$ of the participants were female. Their average age was $31.54 \pm 7.42$ years and $58.3 \%$ of them were married. Sixty-six percent of them had an undergraduate degree, all of them worked at internal medicine clinics $(100.0 \%), 85.4 \%$ of them were clinic nurses and their average work-duration was $8 \pm 6.2$ years (Table 1 ).

Table 1. Descriptive Characteristics of Nurses Working in Internal Medicine Clinics ( $\mathrm{n}=103)$

\begin{tabular}{|c|c|c|}
\hline Characteristics & $\mathbf{n}$ & $\%$ \\
\hline \multicolumn{3}{|l|}{ Sex } \\
\hline Female & 98 & 95.1 \\
\hline Male & 5 & 4.9 \\
\hline \multicolumn{3}{|l|}{ Average Ages $31.54 \pm 7.42$} \\
\hline \multicolumn{3}{|l|}{ Marital Status } \\
\hline Married & 60 & 58.3 \\
\hline Single & 43 & 41.7 \\
\hline \multicolumn{3}{|l|}{ Educational Level } \\
\hline $\begin{array}{c}\text { Vocational health high } \\
\text { school }\end{array}$ & 17 & 16.5 \\
\hline Associate degree & 13 & 12.6 \\
\hline Undergraduate degree & 68 & 66.0 \\
\hline Master's degree & 5 & 4.9 \\
\hline \multicolumn{3}{|c|}{ Clinic Where Nurses Worked } \\
\hline Internal medicine clinics* & 103 & 100.0 \\
\hline \multicolumn{3}{|l|}{ Position at the Clinic } \\
\hline Clinic nurse & 88 & 85.4 \\
\hline Clinic chief nurse & 9 & 8.8 \\
\hline Policlinic nurse & 6 & 5.8 \\
\hline
\end{tabular}

*Oncology, Hematology, Nephrology, Endocrinology, Gastroenterology, Cardiology, Neurology, Chest Diseases Clinics, Intensive Care Units (Internal Medicine, Neurology, Coronary, Chest). 
Table 2. Professionalism Characteristics of Nurses Working in Internal Medicine Clinics ( $\mathrm{n}=103$ )

\begin{tabular}{|c|c|c|c|c|c|c|}
\hline \multirow{2}{*}{$\begin{array}{l}\text { Professionalism Characteristics } \\
\text { 1. Takes individual responsibility for nursing practices }\end{array}$} & \multicolumn{2}{|c|}{$\begin{array}{l}\text { Yes } \\
\text { n } \%\end{array}$} & \multicolumn{2}{|c|}{$\begin{array}{l}\text { No } \\
\mathrm{n} \%\end{array}$} & \multicolumn{2}{|c|}{$\begin{array}{c}\text { Partly } \\
\mathrm{n} \%\end{array}$} \\
\hline & 95 & 92.2 & 5 & 4.9 & 3 & 2.9 \\
\hline 2. Uses simple and clear language to communicate clearly with patients & 93 & 90.3 & 3 & 2.9 & 7 & 6.8 \\
\hline $\begin{array}{l}\text { 3. Uses simple and clear language to communicate effectively with members of } \\
\text { health care team }\end{array}$ & 87 & 84.5 & 3 & 2.9 & 13 & 12.6 \\
\hline 4. Pays attention to division of labor among work colleagues & 87 & 84.5 & 6 & 5.8 & 10 & 9.7 \\
\hline 5. Demonstrates positive attitudes while offering nursing services & 84 & 81.5 & 5 & 4.9 & 14 & 13.6 \\
\hline 6. Wants nursing services to be customized for each patient & 81 & 78.6 & 10 & 9.7 & 12 & 11.7 \\
\hline 7. Designs a work plan for themselves while working & 80 & 77.6 & 8 & 7.8 & 15 & 14.6 \\
\hline 8. Thinks nursing should have a specialization & 80 & 77.6 & 11 & 10.7 & 12 & 11.7 \\
\hline $\begin{array}{l}\text { 9. Always demonstrates correct nursing practices even though other members of } \\
\text { the health care team do not }\end{array}$ & 79 & 76.7 & 7 & 6.8 & 17 & 16.5 \\
\hline $\begin{array}{l}\text { 10. Makes efforts to solve problems with patients and health care team working } \\
\text { together }\end{array}$ & 76 & 73.8 & 7 & 6.8 & 20 & 19.4 \\
\hline $\begin{array}{l}\text { 11. Thinks there are circumstances that would limit professionalism in nursing } \\
\text { profession }\end{array}$ & 73 & 70.8 & 12 & 11.7 & 18 & 17.5 \\
\hline 12. Feels compelled to obey the work rules in nursing practices & 70 & 68.0 & 3 & 2.9 & 30 & 29.1 \\
\hline $\begin{array}{l}\text { 13. Has the necessary knowledge and skills to be a professional in nursing } \\
\text { profession }\end{array}$ & 70 & 67.9 & 8 & 7.8 & 25 & 24.3 \\
\hline $\begin{array}{l}\text { 14. Makes efforts to produce different and customized nursing services for each } \\
\text { patient }\end{array}$ & 70 & 67.9 & 11 & 10.7 & 22 & 21.4 \\
\hline 15. Makes efforts in nursing practices so that patients can develop trust in nurses & 63 & 61.2 & 15 & 14.5 & 25 & 24.3 \\
\hline 16. Performs nursing duties in the most professional manner possible & 62 & 60.2 & 9 & 8.7 & 32 & 31.1 \\
\hline 17. Wants nursing practices to be evaluated by their nursing colleagues & 60 & 58.3 & 19 & 18.4 & 24 & 23.3 \\
\hline 18. Supports association/society related activities & 59 & 57.3 & 21 & 20.4 & 23 & 22.3 \\
\hline 19. Uses evidence-based study results in nursing practices & 52 & 50.5 & 6 & 5.8 & 45 & 43.7 \\
\hline 20. Detects problems of patients in advance & 52 & 50.5 & 3 & 2.9 & 48 & 46.6 \\
\hline $\begin{array}{l}\text { 21. Follows scientific and technological developments and advancements in } \\
\text { nursing }\end{array}$ & 44 & 42.7 & 8 & 7.8 & 51 & 49.5 \\
\hline 22. Creates constructive/positive conditions and actions in nursing practices & 31 & 30.1 & 19 & 18.4 & 53 & 51.5 \\
\hline 23. Belongs to an association/society in nursing & 25 & 24.3 & 79 & 75.7 & - & - \\
\hline 24. Feels the need to use titles of specialist nurse, doctorate nurse & 20 & 19.4 & 76 & 73.8 & 7 & 6.8 \\
\hline
\end{tabular}

When the current study examined the professionalism characteristics of the internal medicine nurses, findings showed that $92.2 \%$ of them took individual responsibility in nursing practices; $90.3 \%$ of nurses used simple and clear language to communicate effectively with patients; $84.5 \%$ of them used simple and clear language in their communication with members of the health care team; $84.5 \%$ of them paid attention to division of labor in working with their team, and $81.5 \%$ of the nurses demonstrated positive attitudes while offering nursing services. Other findings revealed that they wanted nursing services to be specifically customized for each patient $(78.6 \%)$. They also designed a work plan for themselves while working $(77.6 \%)$, and they thought nursing should have specialization (77.6\%). Nurses emphasized correct nursing practices even though other members of the health care team did not $(76.7 \%)$. In addition, $73.8 \%$ of internal medicine nurses made efforts to work with patients and members of the health care team to solve the problems at the clinics. The study results also showed that $70.8 \%$ of them thought there were circumstances that would limit professionalism in the nursing profession. These included a stressful work load, responsibility for too many patients and institutional nursing care policies.

In our study, $67.9 \%$ of the nurses felt the need to obey the work rules in nursing practices. They also had the necessary knowledge and skills to be a professional in the nursing profession, and they made efforts to produce different and customized nursing services for each patient. The study results showed that $61.2 \%$ of the participating nurses made efforts in nursing practices to increase patients' trust in them, and $60.2 \%$ of the nurses tried to consistently carry out their nursing duties in a most professional manner. Nurses wanted nursing practices to be evaluated by their nursing colleagues $(58.3 \%)$, supported association/society related activities $(57.3 \%)$, used evidence-based study results in nursing practices $(50.5 \%)$, and they could detect problems of patients in advance $(50.5 \%)$.

The current study results also showed that $42.7 \%$ of the internal medicine nurses followed scientific and technological developments and advancements in nursing; 
$30.1 \%$ of them found ways to improve nursing practices and to initiate needed changes; $24.3 \%$ of them became a member of an association/society in nursing; and $19.4 \%$ of them felt the need to use titles of specialist nurse, doctorate nurse (Table 2).

\section{Discussion}

Internal medicine nursing is a specialty field in the nursing profession. Among the individual characteristics that nurses should have are the competence and ability to help individuals and the desire to find solutions to their problems. It is important to be professional and to demonstrate these characteristics in internal medicine nursing which serves different patient groups. Determining and developing professionalism characteristics of internal medicine nurses are important in terms of enhancing quality of nursing care [13]. In the current study, it was found that nearly all of the internal medicine nurses took individual responsibility for their nursing practices. This quality ranks first among professionalism characteristics of internal medicine nurses (92.2\%). The American Nurses' Association defines taking individual responsibility as "questioning individuals about their actions". Individual responsibility includes "accountability for colleagues, oneself, those treated, and the institution where they work". Therefore, responsibility does not refer only to fulfilling a duty in line with instructions. It is being willing to carry out the duty and having a certain amount of knowledge and implementing one's own decisions [19]. The study of Jang et al. on oncology nurses found that nurses received the highest score in self-control beliefs as related to their professionalism [11].

A significant number of the study participants reported that they paid attention to using simple and clear language to ensure good communications with their patients $(90.3 \%)$ and team members $(84.5 \%)$. One study identified that nurses who established good communication with patients and members of the health care team demonstrated higher professionalism [5]. The study of Karakoc Kaya et al. reported that nurses who established a good relationship with superiors felt more independent in their profession [20].

It was determined that $84.5 \%$ of the internal medicine nurses paid attention to division of labor in teamwork, and $77.6 \%$ of them designed a work plan for themselves. In order to increase the level of professionalism in the nursing profession, nurses must feel a commitment to and responsibility for their profession and professional identity [11]. Professionalism requires that nurses take responsibility for their own role as part of the team. In addition, they need to be committed to the individual team members' success as well as to the entire team as a unit [6]. This current study found that most of the nurse participants assumed this responsibility.

The first step in establishing a high degree of professionalism begins by considering oneself a professional and demonstrating a professional work ethic [3]. Within the work environment one's colleagues will always evaluate how a person speaks, presents themselves, and performs their job tasks [3, 5]. In keeping with these principles, the goal of nursing professionals is to protect and respect the dignity of patients in their care. The current study results determined that the participating nurses demonstrated positive behaviors while offering nursing services $(81.5 \%)$.

In the current study, the nurses wanted nursing services to be customized for each patient (78.6\%) and made efforts to implement this $(67.9 \%)$. With access to the internet and other sources of information, most individuals know more about nursing services, question these services, and they also expect more when it comes to their health care. Therefore, patient-centered care has now become the focus of an emphasis on quality nursing services [21]. An important part of professionalism includes respecting each patient's individual choices, needs and values. In the current study, we found that many of the nurses achieved these goals successfully.

Another topic of focus for the study participants was their belief that nurses should have an area of specialty within the field of nursing $(77.6 \%)$. The study of Wade found that being a certified nurse increased the quality of patient care given by nurses. They also had greater job satisfaction, professional sensitivity, and a greater sense of responsibility role to their team. The study of Wynd also confirmed that being a certified nurse increased professionalism [8, 22].

Hutchings et al. pointed out that a very important professionalism characteristic for many nurses was the consistent modeling of correct practices, thus ensuring continuity of patient care [23]. Indeed, the current study supports this finding which showed that a significant number of the nurses $(76.7 \%)$ reported that even when their health care team members no longer practiced correct nursing protocols, they were determined to follow through on their tasks in the most professional manner possible.

Nurses bear the responsibilities of developing positive relations, solving conflicts and increasing the quality of nursing care. In addition, the nursing profession requires critical thinking, problem solving, and analyzing skills. In the current study $73.8 \%$ of the nurses made efforts to contribute to the well-being of patients and members of the health care team regarding any problems that arose. These study participants understand the importance of demonstrating their professional characteristics by exercising their autonomy, independence, and respect for others in problem-solving strategies [11]. Furthermore, they also know that the most effective way to attain professionalism characteristics in nursing is to employ critical thinking and scientific problem solving skills [2].

Our study found that $70.8 \%$ of the participating nurses thought there were circumstances that would hinder professionalism in the nursing profession. Factors such as irregular work conditions, a high number of patients per nurse, negative or uncooperative behaviors on the part of health team members or patients, too many responsibilities outside of nursing services and working under intense stress 
impede a nurse's capacity to practice professionalism in nursing [5]. Nonetheless, such negative circumstances highlight the importance of always retaining one's professionalism in nursing.

One of the criteria of professionalism is to abide by work rules and instructions. In our study, $67.9 \%$ of nurses reported that they obey the work rules in their nursing practice. The basic values of professionalism in nursing also require an awareness of professional duties, advocacy, dignity, honesty, autonomy and perfectionism. [6]. In the current study, the fact that most of the nurses felt the necessity to obey the work rules in nursing practices made us conclude that they demonstrated their professionalism and commitment to the duties and tasks of their chosen profession.

A profession encompasses the activities done through knowledge and skills gained with a certain education and training [5]. In the current study, more than half of the internal medicine nurses $(68.0 \%)$ reported that they had the necessary knowledge and skills to be a professional in nursing. This finding made us conclude that more emphasis needs to be put on improving internal medicine nurses' professionalism. Although scientific knowledge and using theory in practice are important characteristics of nursing, Tan et al. reported that the duties and care that nurses provided to patients were dependent on nurses' professional knowledge and skills [13].

Being reliable and trustworthy are particularly important qualities with respect to professionalism characteristics. Bimray and Jooste suggested that nursing care is based on a trust relationship between patient and nurse [6]. Our study results found that the internal medicine nurses $(61.2 \%)$ made efforts in nursing practices to earn the trust of their patients. To earn patients' trust, nurses must exhibit many professional attributes. These include treating patients with dignity and providing fair, defensive and patient-centered nursing services. Nurses must also follow the rules of confidentiality, provide understandable and clear information, and update their knowledge and skills [23].

To achieve professionalism in nursing, the values of this profession must first be named and defined. Thereafter the objectives, tasks, and activities required in the profession of nursing should also be identified. In nursing professionalism, beliefs, opinions, ideas and values (prestige, autonomy, knowledge accumulation, etc.) are integrated [11]. These values enhance safety, ethics and competence in nursing care [6]. In our study, $60.2 \%$ of nurses were always careful to perform their nursing duties in the most professional manner possible. This finding made us conclude that more internal medicine nurses need to work towards this goal. Professionalism is strongly reflected in behaviors and actions demonstrated by nurses. This means that the professional message conveyed by the nurses' practices must coincide with the professional values of being a nurse [6].

Assessment and evaluation of nursing practices by other nursing colleagues are crucial to providing successful health care. In the current study, more than half of the internal medicine nurses $(58.3 \%)$ wanted nursing practices to be evaluated by their colleagues. It is argued that remarks of nursing colleagues help nurses review patient care and shed light on policies and practices that affect the standards and quality of nursing care [21].

One of the significant criteria of professionalism and being a professional is membership in professional societies or associations. This study found that $57.3 \%$ of nurses supported association or society- related activities but only $24.3 \%$ of them were members of such organizations. The purpose of professional societies or associations, which are usually established by members of a certain profession, is to define professional roles, establish professional ethics and policies, strive for professional rights, increase media publicity, help members build group consciousness and pride, empower the profession and motivate professional members [24]. In a study done with nurses, $76.2 \%$ of nurses did not belong to any professional societies or associations [24]. Similarly, the study of Karadag et al. indicated that the rate of nurses' participation in professional organizations, societies or associations was low [25]. In our country, as well, participation in professional organizations, societies or associations was not at a desired level.

Nurses who are devoted to their profession are interested in improving patient care quality and the development of professional characteristics. This requires that nurses incorporate the results of studies and the use of evidence-based practices into their nursing responsibilities. Organizations such as the ICN and the American Association of Colleges of Nursing emphasize that professional nursing should be developed through evidence-based practices. We found that only $50.5 \%$ of study participants used evidence-based study results in their nursing practices. This indicates that more studies should be supported and conducted. Opportunities should also be made available so nurses may attend congresses and symposiums so they may assess and evaluate studies from a critical perspective [26, 27].

Professionalism includes the ability to make an early diagnosis and medical intervention of a patient's needs. This ability has been found to be associated with nurses' motivation, decision-making, happiness and level of burnout [11]. In the current study, $50.5 \%$ of the study participants stated that they were able to diagnose patients' problems in advance. The efficacy of nursing care given to patients depends on nurses' professional knowledge and skills as well as the ability to use these in assessing patient needs [13]. The study of Tan et al., conducted with internal medicine nurses, reported that $54.7 \%$ of nurses had difficulty implementing a care plan and determining a diagnosis [13]. Therefore, to deliver the best care possible, nurses should strive to prioritize a patient's most urgent needs [19]. This current study determined that only half of the nurses had enough knowledge and skills to detect patient difficulties in advance.

In today's world, medical advancements and practices change quickly. Our study found that less than half of the internal medicine nurses (42.7\%) kept abreast of the latest 
scientific and technological developments and advancements in nursing. A study on nurses' participation in scientific activities and events reported that $78.9 \%$ of the nurses had attended professional scientific meetings (congress, symposium, etc.) at least once [28]. The study of Karamanoglu et al. indicated that the rate of nurses who did not join any professional scientific meeting was 50.5\% [5].

Although nurses play an active role in demonstrating their knowledge, abilities, and experience in their nursing practices, only $30.1 \%$ of the nurses in this current study made efforts to create and implement constructive/positive conditions and actions in their nursing practices [23]. One way to make positive change in this regard is to encourage professional nurses to communicate and share information with their colleagues, patients, families and others [6]. Regarding the current study, we believe that internal medicine nurses should receive strong encouragement and support to develop constructive/positive conditions and actions that will improve their nursing practices.

Education is an important feature of professionalism. For this reason, a graduate and/or doctorate degree should be required to work as a professional internal medicine nurse. In the current study, only $19.4 \%$ of the nurses felt that it was necessary for nurses to have a specialty in nursing (requiring graduate studies) or to possess a doctorate degree. The study of Tanaka et al. done with Japanese nurses reported that the professionalism level of nurses was low, and they linked professionalism to possessing a higher education [29]. The same study also found that nurses with higher education degrees scored higher in their professionalism characteristics. However, in the current study $73.8 \%$ of the internal medicine nurses did not believe in the need to use titles of specialist nurse or doctorate nurse in the work environment even if they had achieved these levels of higher education.

\section{Conclusions}

The current study produced the first data to research professionalism characteristics of the nurses who worked at internal medicine clinics in Turkey. Results showed that nurses' willingness to accept individual responsibility for their nursing practices was at a high level, however, their need to use titles of specialist nurse or doctorate nurse was at a low level. Our study results confirmed the need and importance of supporting the growth and development of nurses' professionalism characteristics. We recommend that internal medicine clinic nurses receive support and encouragement to achieve this goal. We also suggest that nurses be encouraged to become members of professional associations, and we emphasize the importance of increasing their expertise and experience by participating in scientific activities and educational programs.

\section{REFERENCES}

[1] Y. Dikmen, H. Karatas, G. G. Arslan, B. Ak, The level of professionalism of nurses working in a hospital in Turkey, Journal of Caring Sciences, Vol.5, No.2, 95-102, 2016.

[2] Kacaroglu Vicdan, A. Professionalism in nursing, Maltepe Universitesi Hemsirelik Bilim ve Sanatı Dergisi, Sempozyum Ozel Sayıs1, 261-263, 2010.

[3] O. Adiguzel, H. Tanriverdi, D. S. Ozkan, Occupational professionalism and the case of nurses as the members of the profession. Journal of Administrative Science, Vol.9, No.2, 235-259, 2011

[4] N. Sahin Orak, S. Ecevit Alpar, Validity and reliability of the Nurses' Professional Values Scale's Turkish version, Journal of Marmara University Institute of Health Sciences Vol.2, No.1, 22-31, 2012.

[5] A. Yavuz Karamanoglu, F. Gok Ozer, A. Tugcu, Evaluation of surgical ward nurses professionalism in their work, in Denizli, Firat Medical Journal, Vol.14, No.1, 12-17, 2009.

[6] B. P. Bimray, K. Jooste, A Conceptual framework of the resemblance in self-leadership and professional core values of nurses in the South African context, African Journal for Physical, Health Education, Recreation and Dance (AJPHERD), Vol.1, No.1, 197-216, 2014.

[7] O. Kavakl1, S. Uzun, F, Arslan, Determination of the professional behavior of the intensive care nurses, Gulhane Medical Journal, Vol.51, No.3, 168-17, 2009.

[8] A.C. Wynd, Current factors contributing to professionalism in nursing, Journal of Professional Nursing, Vol.19, No.5, 25-61, 2003.

[9] Online available from: http://tihud.org.t./main/content?ref=3 \&child $=129$

[10] H. Fesci, N. Dogan, G. P1nar, Nurses working in medical clinics in patients care were faced difficulties and their suggestions for solution, Journal of Anatolia Nursing and Health Sciences, Vol.11, No.3, 40-50, 2008.

[11] I. Jang, Y. Kim, K. Kim, Professionalism and professional quality of life for oncology nurses, Journal of Clinical Nursing, Vol.25, No.19-20, 2835-2845, 2016.

[12] N.M Zakari, N.I Al Khamis, H.Y. Hamadi, Conflict and professionalism: perceptions among nurses in Saudi Arabi, International Nursing Review, Vol.57, No.3, 297-304, 2010.

[13] M. Tan, H. Polat, Z. Akgun Sahin, F. Genc, Motivation level and difficulties encountered in the patient care of nurses working in internal medicine clinics, Cumhuryet Nursing Journal, Vol.4, No.1, 10-17, 2015.

[14] N.B. Dastan, S. Buzlu, The effects of spirituality in breast cancer patients and spiritual care, Maltepe Universitesi Hemsirelik Bilim ve Sanatı Dergisi, Vol.3, No.1, 73-78, 2010 .

[15] T. Karaca, E. D. Ister, Nursing care for patients with COPD on long-term oxygen therapy, Journal of Human Sciences, Vol.13, No.2, 2588-2597, 2016.

[16] D. Whiteside, Perioperative nurse leaders and professionalism, AORN Journal, Vol.104. No.2, 133-144, 2016.

[17] M. ALZadjali, Heart Failure - A public health issue in woman: would heart failure program be cost effective?, Universal Journal of Public Health, Vol.2, No.8, 226-229, 
2014.

[18] S. Celik, F. Hisar, The influence of the professionalism behaviour of nurses working in health institutions on job satisfaction, International Journal of Nursing Practice, Vol.18, No.2, 180-187, 2012.

[19] F. Korkmaz, Professionalizm and nursing in Turkey, Hacettepe University Faculty of Health Sciences Nursing Journal, Vol.18, No.2, 59-67, 2011.

[20] O. Karakoc Kaya, Z. Simsek, F. Kabalcioglu, F.F. Dayı, Hemsirelerin mesleki imajlarını ve meslegi algılama durumlarını etkileyen faktorler. Hemsirelik Forumu Dergisi Ocak-Subat 2004; 7(1):1-6.

[21] C. Hua Han, Measuring patient satisfaction as an outcome of nursing care at a teaching hospital of Southern Taiwan, Journal of Nursing Care Quality, Vol.18, No.2, 143-150, 2003.

[22] H.C. Wade, Perceived effects of specialty nurse certification: a review of the literature, AORN Journal, Vol.89, No.1, 183-92, 2009.

[23] H. Hutchings, F. Rapport, S. Wright, M. Doel, A. Jones, Obtaining consensus about patient-centred professionalism in community nursing: nominal group work activity with professionals and the public, Journal of Advanced Nursing,
Vol.68, No.11, 2429-2442, 2011.

[24] F. Korkmaz, S. Gorgulu, Viewpoint of nurses on nursing in respect to professionalism criteria, Hacettepe University Faculty of Health Sciences Nursing Journal, Vol.17, No.1, $1-17,2010$.

[25] A. Karadag, F. Hisar, N. Ozhan Elbas, The level of professionalism among nurses in Turkey, Journal of Nursing Scholarship, Vol. 39, No.4, 371-374, 2007.

[26] J.O. Halabi, A. Hamdan-Mansou, Attitudes of Jordanian nursing students towards nursing research, Journal of Research in Nursing, Vol.17, No.4, 363-373. 2010.

[27] American Association of Colleges of Nursing (AACN). Position statement on nursing research, Online available from: http://www.aacn.nche.edu/publications/position/Nsg Research.pdf 13.01.2016

[28] M. Kelleci, Z. Golbaşı, M. Yılmaz, S. Dogan, Determine nurses' views about researching and whether nurses utilize research's results in nursing care, Turkish Journal of Research \& Development in Nursing, Vol.10, No.2, 3-16, 2008.

[29] M. Tanaka, Y. Yonemitsu, R. Kawamoto, Nursing professionalism: A national survey of professionalism among Japanese nurses, International Journal of Nursing Practice, Vol.20, No.6, 579-587, 2014. 